\title{
Performance potential of low-defect density silicon thin-film solar cells obtained by electron beam evaporation and laser crystallisation
}

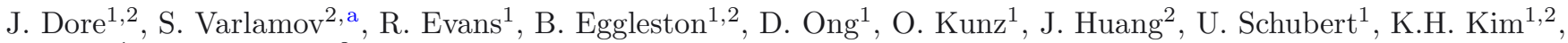 \\ R. $\operatorname{Egan}^{1}$, and M. Green ${ }^{2}$ \\ 1 Suntech R\&D Australia, Pty., Ltd. 82-86 Bay St., Botany, NSW 2019, Australia \\ ${ }^{2}$ University of NSW Sydney, NSW 2052, Australia
}

Received: 30 July 2012 / Received in final form: 26 November 2012

Published online: 11 January 2013

(C) Dore et al., published by EDP Sciences, 2013

\begin{abstract}
A few microns thick silicon films on glass coated with a dielectric intermediate layer can be crystallised by a single pass of a line-focused diode laser beam. Under favorable process conditions relatively large linear grains with low defect density are formed. Most grain boundaries are defect-free low-energy twin-boundaries. Boron-doped laser crystallised films are processed into solar cells by diffusing an emitter from a phosphorous spin-on-dopant source, measuring up to $539 \mathrm{mV}$ open-circuit voltage prior to metallisation. After applying a point-contact metallisation the best cell achieves $7.8 \%$ energy conversion efficiency, open-circuit voltage of $526 \mathrm{mV}$ and short-circuit current of $26 \mathrm{~mA} / \mathrm{cm}^{2}$. The efficiency is significantly limited by a low fill-factor of $56 \%$ due to the simplified metallisation approach. The internal quantum efficiency of laser crystallised cells is consistent with low front surface recombination. By improving cell metallisation and enhancing light-trapping the efficiencies of above $13 \%$ can be achieved.
\end{abstract}

\section{Introduction}

Crystalline silicon (c-Si) wafer-based solar cells dominate the photovoltaic (PV) market due to the mature and constantly improving technology and a decreasing manufacturing cost. One of the major contributors into cost reduction is the use of thinner cells to lower the consumption of the material. A number of approaches exist to produce thin c-Si wafers and layers [1]. c-Si films on supporting substrates such as glass is one of such approaches and a few technologies have been developed to produce solar cells from such films [2-6]. The highest module efficiency of c-Si thin-film solar cells on glass is $10.5 \%$ [4]. Further improvement in the cell performance is limited by the high density of intragrain defects and related poor electronic quality of the material $[7,8]$ typically obtained by solidphase crystallisation (SPC) or epitaxy (SPE) at relatively low temperatures compatible with the glass substrate. A new approach has recently emerged that exploits zonemelt-like liquid-phase crystallisation (LPC) of precursor silicon films by an electron beam to produce large-grained and low-defect density c-Si films on glass with the superior

\footnotetext{
${ }^{a}$ e-mail: s.varlamov@unsw.edu.au
}

electronic quality compared to $\mathrm{SPC}$ silicon $[9,10]$. The open circuit voltage $\left(V_{O C}\right)$ of $545 \mathrm{mV}$ and the efficiency of $4.7 \%$ were demonstrated for a cell with a LPC absorber and an a-Si:H heterojunction emitter. This paper presents initial results for a similar approach but where a diode laser is used for the LPC to obtain high crystallographic and electronic quality Si films. These films are processed into $7.8 \%$ efficient cells with a diffused homojunction emitter.

\section{Experiment}

Planar Schott Borofloat33 glass was used as a substrate for film deposition. It was coated with an intermediate dielectric layer, such as $\mathrm{SiC}_{x}, \mathrm{SiO}_{x}, \mathrm{SiN}_{x}$ or their combination. These layers, intrinsic or boron-doped, were prepared by RF magnetron sputtering or co-sputtering using dielectric and pure boron targets. Then, $10 \mu \mathrm{m}$ thick Si films, undoped or boron doped at $1 \mathrm{E} 16 \mathrm{~cm}^{-3}$, were deposited by electron-beam evaporation at $650^{\circ} \mathrm{C}$ on borondoped or undoped intermediate layer respectively. The Si films were crystallised by a single pass of a line-focus beam from an $808 \mathrm{~nm}$ CW diode laser, LIMO450-L12 × 0.3DL808-EX937. The laser beam has a Gaussian profile in 
the short (scan) direction (FWHM $0.170 \mathrm{~mm}$ ) and a tophat profile in the long direction (FWHM $12 \mathrm{~mm}$ ). The laser conditions were $15-25 \mathrm{~kW} / \mathrm{cm}^{2}$ and $10-15 \mathrm{~ms}$ exposure time at sample stage pre-heat temperature in the range of $550-700{ }^{\circ} \mathrm{C}$. Solar cells of $1.7 \times 0.6 \mathrm{~cm}^{2}$ size were fabricated in the middle of the crystallised strips. The cell emitter was formed by phosphorous diffusion at about $900{ }^{\circ} \mathrm{C}$ from a spin-on source. The hydrogen plasma passivation and metallisation processes applied to the cells are similar to those used for SPC Si thin-film solar cells [4-6]. Metallisation relies on forming point contacts on the rear side of the device by inkjet printing holes in a resin layer and then etching down to the emitter and absorber layers in sequence. Sputtered $\mathrm{Al}$ is then used to form contacts to the $n$ - and $p$-type openings. This metallisation is very similar to the one described in [11] but simplified by reducing the contact density and no heavy Si doping under the $p$-type contacts to the absorber to accommodate and facilitate quicker cell development. Current research-level planar cells rely on a pigmented rear diffuse reflector for modest light-trapping.

The Si film crystal quality was characterised by SEM and TEM imaging. The dopant concentration in the films was estimated from SIMS measurements. The electronic film quality and the cell performance was characterised by Hall measurements, Suns- $V_{o c}$, Light $I-V$ and spectral response techniques.

\section{Results and discussion}

A few micron thick e-beam evaporated Si films can be crystallised in a quick, zone-melt like process by scanning with a high power line-focus diode laser beam. Continuous lateral crystal growth can be achieved whereby the growth front is seeded by the preceding crystallised region, forming long parallel grains in the direction of scanning (Fig. 1). Factors having significant effects on the crystallisation process include an intermediate layer between glass and $\mathrm{Si}$, laser beam parameters and the substrate temperature during crystallisation.

\subsection{Intermediate layer}

The intermediate layer has to be stable at the Si melting point of $1414{ }^{\circ} \mathrm{C}$ and it serves a few important functions: enables molten $\mathrm{Si}$ to wet substrate sufficiently to avoid balling up; blocks impurity diffusion from glass; acts as a dopant source; provides an antireflection (AR) effect; and passivates the front device surface (the Si-glass interface). Transparent dielectric films, $\mathrm{SiO}_{x}, \mathrm{SiC}_{x}$, and $\mathrm{SiN}_{x}$, and their different combinations were tested as the intermediate layers, along with their interactions with laser beam parameters. Properties of different intermediate layers and their effects on cell performance are described in detail elsewhere $[11,12]$. No single layer alone can perform all required functions. $\operatorname{SiC}_{x}$ (refractive index $(n)=2.9$ ) is the best wetting layer providing the widest laser process window but it allows impurity diffusion from glass, absorbs too much of the short wavelength light $<500 \mathrm{~nm}$, and it does not passivate the Si-glass interface well (Sect. 3.4). $\mathrm{SiO}_{x}$ is the best impurity diffusion barrier and the surface passivating layer resulting in the highest $V_{O C}$ but because its refractive index is very similar to that of the superstrate glass $(n=1.51)$ it does not offer any additional AR effect to that already provided by the glass alone and it has the smallest laser process window. $\operatorname{SiN}_{x}(n=2.11)$ offers the best AR effect and a reasonably wide laser parameter widow but it leads to pinholing and the poorest cell performance. Only a combination of different dielectrics is proved to deliver a satisfactory process and cell performance. Results presented in this report are obtained using a three layer stack of $\mathrm{SiO}_{x} / \mathrm{SiC}_{x} / \mathrm{SiO}_{x}(\mathrm{O} / \mathrm{C} / \mathrm{O}, 80 \mathrm{~nm}$, $14 \mathrm{~nm}, 15 \mathrm{~nm}$ respectively). The oxide layers in the stack are boron-doped at a level of $4 \sim 5 E 19 \mathrm{~cm}^{-3}$ (estimated from SIMS measurements) such that after boron diffusion that occurs during laser melting the sheet resistance of crystallised Si films is about $2000 \Omega / \mathrm{sq}$ and the boron concentration of about $1 \mathrm{E} 16 \mathrm{~cm}^{-3}$.

\subsection{Laser process}

The range of laser parameters that allows a successful crystallization process is limited by the resulting Si crystal structure at the lower energy-dose end, which has to avoid amorphous and/or microcrystalline material, and by dewetting of a Si film from the substrate at the high dose end. Without any intermediate wetting layer, and without substrate heating dewetting and/or delamination occurs at energy doses comparable with the crystallisation limit and no process is feasible.

With the intermediate layer, a large-grained crystalline silicon material without dewetting or delamination is obtained at substrate temperatures exceeding the glass softening point of about $550^{\circ} \mathrm{C}$ and the minimum laser energy dose of $220 \mathrm{~J} / \mathrm{cm}^{2}$. The experimentally determined process window for the dose is about 250,220 and $190 \mathrm{~J} / \mathrm{cm}^{2}$ wide for the $\mathrm{SiC}_{x}, \mathrm{SiN}_{x}$ and $\mathrm{SiO}_{x}$, intermediate layer respectively. The cells on the $\mathrm{O} / \mathrm{C} / \mathrm{O}$ intermediate layer coated glass presented in this report typically require the energy dose of $240-260 \mathrm{~J} / \mathrm{cm}^{2}$.

\subsection{Structural quality}

The optimised laser crystallisation process results in lateral growth of linear silicon grains which extend through the whole film thickness of $10 \mu \mathrm{m}$ and they are a few millimetres long and 50-500 $\mu \mathrm{m}$ wide (Fig. 1). According to electron backscatter diffraction (EBSD) most of the linear grains have [101] orientation in direction normal to the film plane [13]. TEM cross-sectional images and their corresponding diffraction patterns (Figs. 2, 3) confirm complete crystallisation with [110] grain orientation in direction parallel to the film. It is consistent with the EBSD images from [13] as EBSD and TEM are measured at approximately $90^{\circ}$ relative to each other. The silicon grains contain regions with the varying defect density which was evaluated by counting dislocation lines 


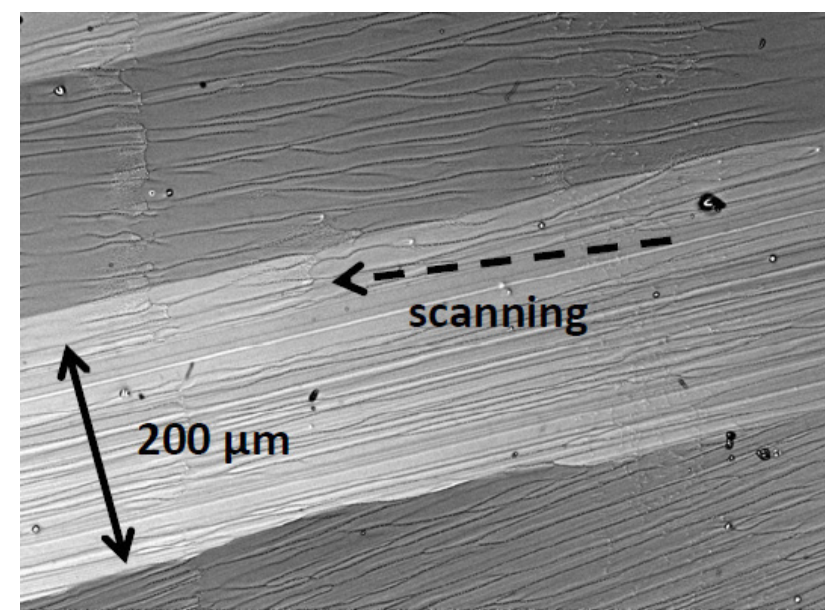

Fig. 1. Backscatter SEM image of lateral grains in diode laser crystallised Si film. $\sim 200 \mu \mathrm{m}$-wide linear grains are shown in the same shade of grey; wavy lines within each grain are surface texture developed during crystallisation while straight parallel lines are twin boundaries.

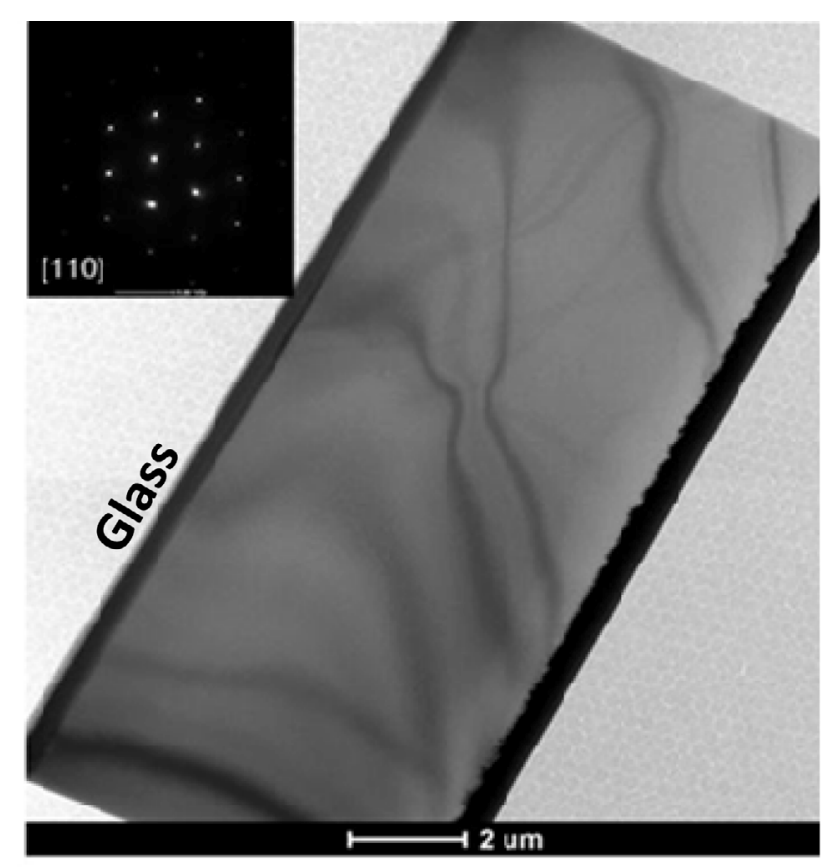

Fig. 2. TEM image and diffraction pattern of defect-free grain with [110] orientation in diode laser crystallised Si film.

in Weak-Beam-Dark-Field (WBDF) images. Most laterally grown grains are nearly defect-free on the TEM scale which translates into the defect density of $1 \mathrm{E} 5 \mathrm{~cm}^{-2}$ or lower (Fig. 2) while the most defect-rich grains can contain dislocations with the density up to $1 \mathrm{E} 9 \mathrm{~cm}^{-2}$ (Fig. 3). The most commonly observed boundaries between linear grains are defect-free low-energy $\Sigma 3$ twin-boundaries which are electrically inactive, i.e. they do not significantly contribute into carrier recombination $[10,14]$.

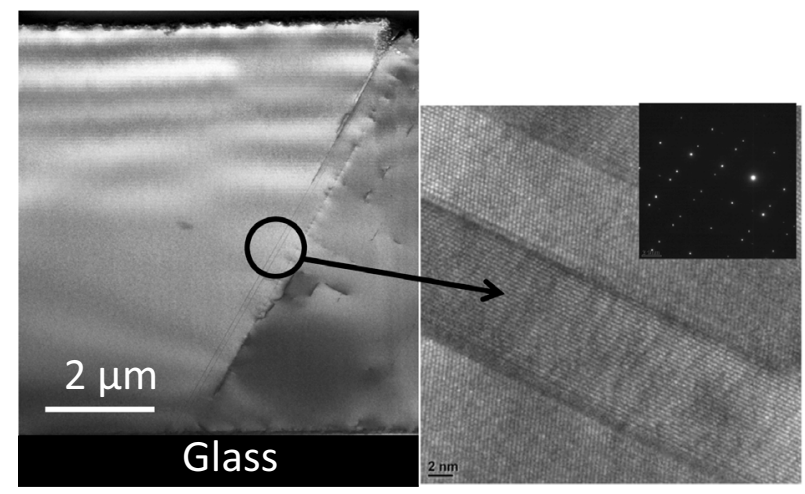

Fig. 3. (Left) TEM image of diode laser crystallised Si grains with twin boundary (circle) and dislocations; (right) high resolution TEM image of defect-free twin boundary.

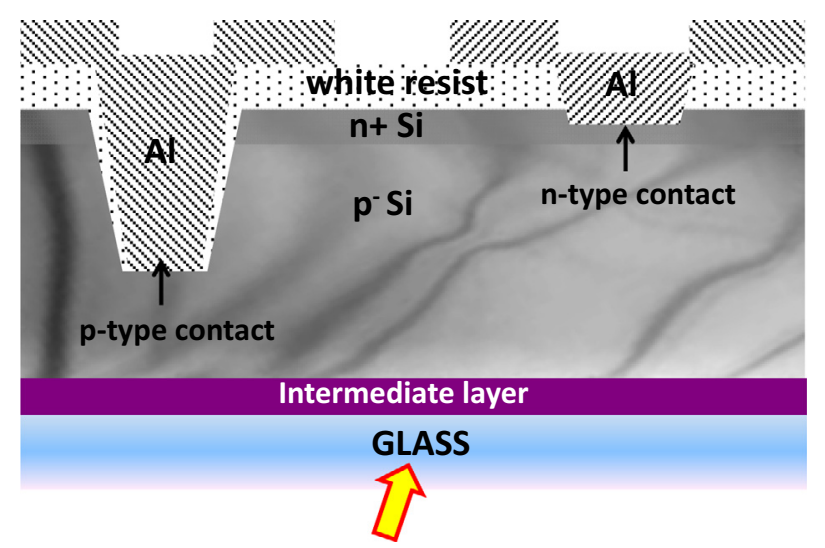

Fig. 4. The structure of a metallised solar cell. The light enters the cell through the front, glass side.

\subsection{Electronic properties and cell performance}

The carrier mobility, concentration and bulk resistivity of laser crystallised boron-doped Si films used for cell fabrication were calculated from Hall effect measurements using the Van der Pauw cross pattern. Depending on a particular location the mobility typically varies between 300 and $470 \mathrm{~cm}^{2} / \mathrm{V} \mathrm{s}$, the carrier concentration $\sim 10 \mathrm{E} 16 \mathrm{~cm}^{-3}$, and resistivity $1-3 \Omega \mathrm{cm}$. These values are similar to those measured for a reference c-Si wafer: $414 \mathrm{~cm}^{2} / \mathrm{V} \mathrm{s}, 1.6 \mathrm{E} 16 \mathrm{~cm}^{-3}, 0.94 \Omega \mathrm{cm}$ respectively, indicating a high electronic quality of the laser crystallised silicon film, which is a lot better than the quality of a reference SPC Si film with a similar boron concentration and a mobility of $50-120 \mathrm{~cm}^{2} / \mathrm{V} \mathrm{s}$, which is in agreement with the mobilities of $40-90 \mathrm{~cm}^{2} / \mathrm{V}$ s reported elsewhere [15].

The structure of a metallised solar cell is shown in Figure 4.

The cell voltages depend on the intermediate dielectric layers, which is discussed elsewhere $[11,12]$. The cells on $\mathrm{SiO}_{x}$ achieve $V_{O C}$ in a range of $520-540 \mathrm{mV}$, while the cells on $\mathrm{SiN}_{x}$ have the poorest $V_{O C}$, below $500 \mathrm{mV}$. These effects are not well understood but it can be speculated that the oxide provides the best silicon-glass interface passivation which is consistent with high blue response for cells on $\mathrm{SiO}_{x}$ (Fig. 5, right). For cells on $\mathrm{SiN}_{x}$ SIMS data indicate 

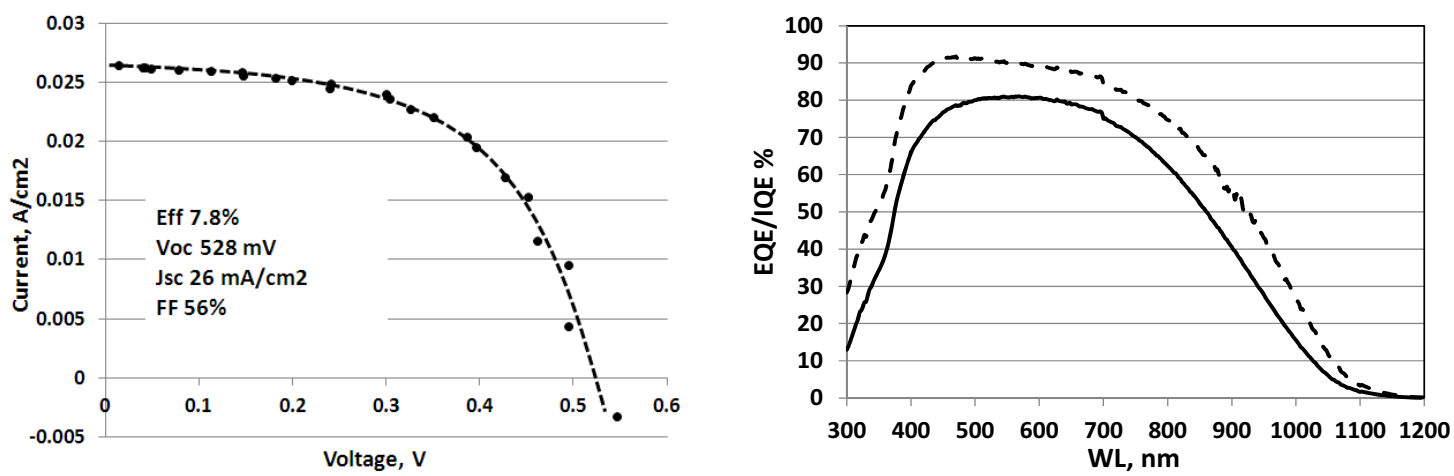

Fig. 5. (Left) Light $I-V$ curve and (right) EQE (solid) and $I Q E$ (broken) of $7.8 \%$ efficient laser crystallised Si thin-film cell.

presence of nitrogen contamination which can be negatively affecting the voltages. The best performing metallised $7.8 \%$-efficient cell on the $\mathrm{O} / \mathrm{C} / \mathrm{O}$ triple layer stack has $V_{O C}$ of $526 \mathrm{mV}$, similar to $V_{O C}$ of the cells on the oxide only but an improvement in cell antireflection properties due to presence of a very thin $\mathrm{SiC}_{x}$ layer on the front leads to a significant current gain, $26 \mathrm{~mA} / \mathrm{cm}^{2}$ versus $24 \mathrm{~mA} / \mathrm{cm}^{2}$ for the cell on $\mathrm{SiO}_{x}$ [11].

The light $I-V$ curve of the best, $7.8 \%$ efficient cell is shown in Figure 5 (left).

The series and shunt resistances $\left(R_{s}\right.$ and $\left.R_{s h}\right)$ of 4.5 and $317 \Omega \mathrm{cm}^{2}$ respectively, were estimated by measuring the inverse slope of the $I-V$ curve at the voltage and current axes. High $R_{s}$ is due to poor metal contacts that are made to lightly-doped $\left(\sim 1 \mathrm{E} 16 \mathrm{~cm}^{-3}\right)$ silicon. It is also possible that a Schottky diode is formed at such contacts, which has a negative contribution to the cell voltage [16]. A source of relatively low $R_{s h}$ is not yet identified. Both high $R_{s}$ and low $R_{s h}$ result in the low $F F$ of $56 \%$. It can be shown [17] that $R_{s}$ of $4.5 \Omega \mathrm{cm}^{2}$ results in the $F F$ reduction of about $13 \%$, from nominal $70 \%$, typical for poly-Si thin-film cells with a similar metallisation scheme and $R_{s}$ of $1.3 \Omega \mathrm{cm}^{2}[4,6]$, to $57 \%$, in a good agreement with the measured $F F$ value. It is also estimated that $R_{s h}$ of $317 \Omega \mathrm{cm}^{2}$ can be responsible for only about $3 \%$ reduction in the FF. Both these issues can be addressed by improving cell metallisation, for example, by selectively doping the contacts to the absorber. With the FF of at least $70 \%$, which is typical for optimised contact schemes of this type [18], the cell efficiency would approach $10 \%$.

The EQE, and $I Q E$ curves of the best cell are shown in Figure 5 (right). The $I Q E$ is adjusted to take into account parasitic absorption in the $\mathrm{SiC}_{x}$ layer, which was measured prior to silicon deposition, as presented in [11]. The IQE peaks at around $90 \%$ and it stays around this value for most of the visible wavelength range. For a rear-junction cell it suggests the low front surface recombination velocity and the minority carrier diffusion length greater than the cell thickness of $10 \mu \mathrm{m}$.

\subsection{Performance potential}

In order to estimate the performance potential of the laser crystallised silicon material the cell $I Q E$ was fitted by using PC1D modelling. This allows indicative values of bulk lifetime $(\tau)$ and front surface recombination velocity $\left(S_{F}\right)$ to be extracted. The rear-surface recombination velocity was found to have no impact on the $I Q E$ in this model, which is likely due to the low minority carrier concentration at the heavily doped $n+$ rear surface.

The best $7.8 \%$ efficient cell is difficult to model because of complexity of its optical properties in the shortwavelength region due to presence of the triple $\mathrm{O} / \mathrm{C} / \mathrm{O}$ intermediate layer stack on the front. Instead, a similar cell but on the single $\mathrm{SiO}_{x}$ layer was used. It is justified because both cells have similar $V_{O C}$ and similarly high $I Q E$ in the visible region (Figs. 5 and 6 ). The oxide film and the glass were treated as one $3.3 \mathrm{~mm}$ thick layer with the refractive index of 1.5 .

Possible ranges for $\tau$ and $S_{F}$ can be estimated by looking at two extreme cases. The case when recombination is dominated by the front surface can be modelled by setting $\tau$ very high (e.g. $100 \mu \mathrm{s})$. In this case, a good IQE fit with maximum of $93 \%$ is achieved when $S_{F}=1900 \mathrm{~cm} / \mathrm{s}$ or less (blue dotted line in Fig. 6). Similarly, the case dominated by bulk recombination is modelled by setting $S_{F}$ very low (e.g. to $100 \mathrm{~cm} / \mathrm{s})$. In this case, a good $I Q E$ fit is obtained when $\tau=260$ ns or more (purple dotted line in Fig. 6). Thus, we can conclude from using this model that $\tau$ is at least $260 \mathrm{~ns}$, and that $S_{F}$ is at most $1900 \mathrm{~cm} / \mathrm{s}$. At present, there is no indication as to which case, bulk or surface recombination, limits the cell performance. The parameters used to obtain the best fits are listed in Table 1.

Even at the minimum value of $260 \mathrm{~ns}$, the lifetime would be sufficient for significantly higher efficiencies, should all other device properties be optimised. This is instructive because it shows that the achieved cell performance is not limited by the laser crystallised material quality and thus identifies device optimisation as the immediate development priority leading to better cell performance, rather than the silicon material itself. For example, an ideal cell with $R_{s}$ of $1-1.5 \Omega \mathrm{cm}^{2}$ (e.g. with selectively doped absorber contacts), no shunts, optimum antireflection coating and internal reflectance of over $90 \%$ (e.g. via light-trapping by surface texture as described in [19]) would be potentially capable of an efficiency of over $13 \%$. 
Dore et al.: Performance potential of diode laser crystallised silicon thin-film solar cells

Table 1. PC1D model parameters.

\begin{tabular}{lc}
\hline Thickness $[\mu \mathrm{m}]$ & 10 \\
\hline$p$-type background doping $\left[\mathrm{cm}^{-3}\right]$ & $7 \mathrm{E} 15$ \\
Peak $n$-type emitter doping $\left[\mathrm{cm}^{-3}\right]$ & $1.5 \mathrm{E} 19$ \\
Bulk lifetime $[\mu \mathrm{s}]\left(\right.$ bulk-limited; $\left.S_{F}=100 \mathrm{~cm} / \mathrm{s}\right)$ & 0.26 \\
Rear-surface recombination velocity $[\mathrm{cm} / \mathrm{s}]$ & $1 \mathrm{E} 4$ \\
Front-surface recombination velocity $[\mathrm{cm} / \mathrm{s}]$ & 1900 \\
(surface-limited, $\tau=100 \mu \mathrm{s})$ & \\
Front internal reflectance $[\%]$ & 51 \\
Rear internal reflectance $[\%]$ & 58 \\
\hline
\end{tabular}

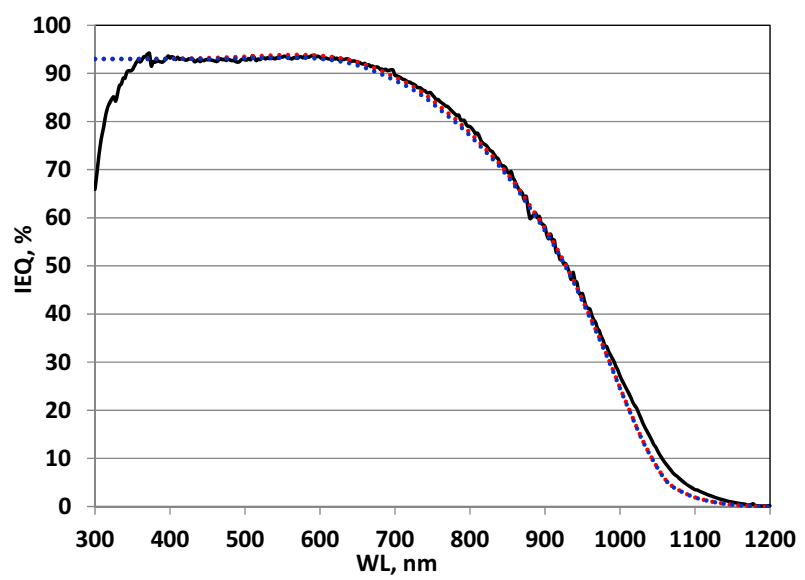

Fig. 6. Experimental (black-solid line) IQE curve and frontsurface (blue-dotted line) and bulk recombination (red-dotted line) limited model fits of the cell on the oxide layer.

\section{Conclusions}

It is demonstrated than line-focused diode laser crystallisation of a few micron thick silicon films on glass can produce a high crystal and electronic quality material. Such a material consists of a few millimetre long and 50-500 micron wide grains with low defect density. The majority of grains boundaries are defect free low-energy $\Sigma 3$ twin boundaries. Laser process parameters, crystal and electronic film and cell properties are influenced by an intermediate dielectric layer between glass and silicon. Solar cells with a diffused emitter that are fabricated on the $\mathrm{SiO}_{x}$ layer achieve the highest $V_{O C}$ up to $539 \mathrm{mV}$. The cells on the $\mathrm{SiO}_{x} / \mathrm{SiC}_{x} / \mathrm{SiO}_{x}$ triple stack layer achieve the best efficiency up to $7.8 \%$. The performance is not limited by the quality of the laser crystallised Si material but by simplified device design and poor light-trapping. PC1D modelling suggests a bulk lifetime of at least $260 \mathrm{~ns}$, which in an otherwise optimised device, would be compatible with efficiencies of over $13 \%$. Future work will focus on device optimisation to determine how much of this improvement is achievable.

\section{References}

1. F.J. Henley, in Proceedings of the IEEE Photovoltaic Specialist Conference, Honolulu, USA, 2010, p. 1184

2. H.M. Branz, C.W. Teplin, M.J. Romero, I.T. Martin, Q. Wang, K. Alberti, D.L. Young, P. Stradin, Thin Solid Films 519, 4545 (2011)

3. I. Gordon, L. Carnel, D. Van Gestel, G. Beaucarne, J. Poortmans, Prog. Photovolt.: Res. Appl. 15, 574 (2007)

4. M. Keevers, T. Young, U. Schubert, M. Green, in Proceedings of the 22 European Photovoltaic Solar Energy Conference, Milan, Italy, 2007

5. O. Kunz, Z. Ouyang, S. Varlamov, A. Aberle, Prog. Photovolt.: Res. Appl. 17, 567 (2009)

6. R. Egan et al., in Proceedings of the 24 European Photovoltaic Solar Energy Conference, Hamburg, Germany, 2009

7. J. Wong, J. Huang, B. Eggleston, M.A. Green, O. Kunz, R. Evans, M. Keevers, R.J. Egan, J. Appl. Phys. 107, 123705 (2010)

8. J. Wong, J. Huang, S. Varlamov, M. Green, M. Keevers, Prog. Photovolt.: Res. Appl. (2011),

DOI : $10.1002 /$ pip. 1154

9. D. Amkreutz, J. Muller, M. Schmidt, T. Hanel, T.F. Schulze, Prog. Photovolt.: Res. Appl. 19, 937 (2011)

10. W. Seifert, D. Amkreutz, T. Arguirov, M. Krause, M. Schmidt, Solid State Phenomena 178-179, 116 (2011)

11. J. Dore, R. Evans, U. Schubert, B. Eggleston, D. Ong, K. Kim, J. Huang, O. Kunz, M. Keevers, R. Egan, S. Varlamov, M. Green, Prog. Photovolt.: Res. Appl., DOI : $10.1002 /$ pip. 2282

12. J. Dore, R. Evans, B. Eggleston, S. Varlamov, M. Green, MRS Online Proceedings Library 1426 (2012), Doi:10.1557/opl.2012.866

13. B. Eggleston, S. Varlamov, J. Huang, R. Evans, J. Dore, M. Green, MRS Online Proceedings Library 1426 (2012), Doi: 10.1557/opl.2012.1260

14. J. Chen, T. Sekiguchi, D. Yang, F. Yin, K. Kido, S. Tsurekawa, J. Appl. Phys. 96, 5490 (2004)

15. T. Noguchi, Jpn J. Appl. Phys. 32, L1584 (1993)

16. S.W. Glunz, J. Nekarda, H. Mäckel, A. Cuevas, in Proceedings of the 22 European Photovoltaic Solar Energy Conference, Milan, Italy, 2007, p. 849

17. M.A. Green, Solar Cells (University of NSW, 1992), p. 97

18. S. Partlin, N. Chang, R. Egan, T. Young, D. Kong, R. Evans, D.A. Clugston, P. Lasswell, A. Turner, J. Dore, T. Florian, in Proceedings of the 25 European Photovoltaic Solar Energy Conference, Valencia, Spain, 2010, p. 3568

19. Q. Wang, T. Soderstrom, K. Omaki, A. Lennon, S. Varlamov, Energy Procedia 15, 220 (2012) 